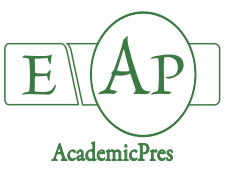

Usta $\mathrm{M}$ et al. (2020)

Notulae Botanicae Horti Agrobotanici Cluj-Napoca 48(2):523-534

DOI: $10.15835 /$ nbha 48211822

Research Article

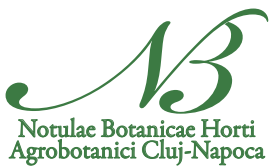

\title{
The molecular characterization of the coat protein sequence and differentiation of CMV - subgroup I on tobacco from native flora in Turkey
}

\author{
Mustafa USTA ${ }^{1 *}$, Abdullah GÜLLER ${ }^{2}$, Abidin GÜNAY ${ }^{1}$ \\ ${ }^{1}$ Van Yuzuncu Yil University, Faculty of Agriculture, Department of Plant Protection, Van, Turkey; \\ mustafausta@yyu.edu.tr ('correspondingauthor);gunayabidin@hotmail.com \\ ${ }^{2}$ Bingöl University, Faculty of Agriculture, Department of Plant Protection, Bingöl; Turkey; gullerabdullah@hotmail.com
}

\begin{abstract}
Cucumber mosaic virus (CMV) has a broad plant-host range and a wide ecological zone distribution. Virus-like symptoms were observed on tobacco fields of Adiyaman province (Turkey) showing conspicuous mottling, greenish mosaic patterns and severe malformations of leaves. A total of forty tobacco samples tested positive against CMV by reverse transcription polymerase chain reaction (RT-PCR) using coat protein gene specific primers. Five randomly chosen CMV isolates were cloned into pGEM T-Easy vector and transformed into Escherichia coli JM109 strain. The recombinant bacterial clones containing insert-DNA were further purified and sequenced bidirectionally. In multiplex-RT-PCR studies carried out, it was found that all $40 \mathrm{CMV}$ isolates belong to Subgroup I by resulting a 593 bp long DNA fragments. CMV subgroup IA was found to predominate in 4 out of 5 tobacco samples and CMV subgroup IB was found in 1 out of $5 \mathrm{CMV}$-positive samples by comparing the isolates with CMV reference isolates in phylogenetic tree. However, no Subgroup II sequences were found by multiplex RT-PCR using discriminating primers. The nucleic acid sequences were analyzed for the investigation of diversity of coat protein $(\mathrm{CP})$ sequences of $5 \mathrm{CMV}$ isolates. The sequence similarity ranged from $94.2-100 \%$ with the CMV subgroup I isolates infecting diverse plants in other regions of the world. The evolutionary tree revealed that the CMV IA Adiyaman isolates exhibited a genetic affinity with Australian and Spanish isolates. However, the CMV IB Adiyaman isolate showed a close genetic relationship with only the Australian isolates. To our knowledge, this study shows for the first time the occurrence of CMV IA and IB isolates infecting cultured tobacco plants in Adiyaman province.
\end{abstract}

Keywords: characterization; cloning; cucumber mosaic virus; phylogeny; subgroup

\section{Introduction}

Tobacco (Nicotiana tabacum L.) is one of the substantial economic products and is grown in most countries such as Brazil, Turkey, Canada, USA, and China where it represents primary producing fields (FAO, 2013). Virus-borne diseases frequently lead to reduced quality of product and yield. Tobacco crops are attacked by numerous viruses such as potato Y potyvirus (PVY), tobacco ringspot nepovirus (TRSV), pepper mottle potyvirus (PeMoV), cucumber mosaic cucumovirus (CMV), alfalfa mosaic alfamovirus (AMV), tobacco leaf 
curl geminivirus (TbLCV), tobacco etch potyvirus (TEV), tobacco mosaic tobamovirus (TMV), tomato spotted wilt tospovirus (TSWV) and become epidemic in many tobacco cultivated areas (Valand and Muniyappa, 1992; EPPO/CABI, 1996b; Chatzivassiliou, 2008; Chen et al., 2014; Akinyemi et al., 2016).

Adiyaman is traditionally one of the oldest tobacco planting provinces of Turkey which is well known for its local tobacco. Adiyaman's tobacco is an important source for rural income, ranking $5^{\text {th }}$ with its $8 \%$ tobacco production of Turkey (TUIK, 2015). Single, double or multiple virus infections can potentially destroy the tobacco crops, if it is planted on a large scale. Cucumber mosaic virus (CMV) is considered important host of tobacco, which has a wide array of hosts capable of making epidemics in more than 1300 plant species (Garcia-Arenal and Palukaitis, 2008).

CMV, belonging to the Bromoviridae family, was firstly recorded in cucumber and melon cultivation areas in USA in 1916 (Doolittle, 1916), thereafter recognized in various agricultural and ornamental plants from other numerous countries such as Argentina, India, Korea, China in temperate and tropical regions (Rodríguez Pardina et al., 2013; Nagendran et al., 2018; Park et al., 2018).

$\mathrm{CMV}$ is a destructive disease in $N$. tabacum with symptoms like mosaic, deformation, dwarfing and sometimes necrosis in infected plants depending on the variety of plant and viral isolate, weather conditions, existence of satellite RNA, pathogenicity, and co-existing infections (Palukaitis et al., 1992). It possesses an isometric-shaped, tripartite (+) ssRNA genome of approximately $29-30 \mathrm{~nm}$ diameters, without envelopes. This genome is encapsidated in separate particles, which are RNA-4 (also referred to as subgenomic RNA), RNA-3, RNA-2 and, RNA-1 in increasing length (Palukaitis and Garcia-Arenal, 2003). CMV has been transmitted experimentally by plant sap and non-persistently in more than 75 species of a stylet-borne aphids from plant to plant, especially from Myzus persicae and Aphis gossypii (Kaplan et al., 1997).

CMV isolates are principally categorized into two parts as subgroup I and subgroup II (SI and SII) based on serological tests, triplet mapping of coat protein (CP) gene, RT- PCR followed by RFLP analyses, nucleic acid hybridization, and nucleotide sequence similarity. Furthermore, SI is subdivided into the subgroup IA (SIA) and subgroup IB (SI-B) depending on the analysis of open reading frame gene, untranslated region sequences of RNA3 and a cladistic assay of the $\mathrm{CP}$ gene. Such a classification has been reported and supported by various researchers (Palukaitis et al., 1992; Roossinck, 2002; Lin et al., 2003).

The presence of CMV and its subgroups has been reported in many international and national studies with different tests in different hosts (Kaplan et al., 1997; Rodríguez Pardina et al., 2013). However, studies on subgroup discrimination of this virus nationwide are limited. Although it is a widespread virus in many crops, little is known about the molecular features of Turkish tobacco isolates and their subgroups they belong. This research has addressed the categorization and molecular analysis of $5 \mathrm{CMV}$ strains at the genomic level in symptomatic tobacco plants from Adiyaman province of Turkey.

\section{Materials and Methods}

\section{CMV isolates}

A total of $40 \mathrm{CMV}$ isolates included in this paper were obtained from our previous tobacco field survey performed during the period from August to September 2018 in Adiyaman province, located in southeast region of Turkey (Günay, 2019). Plant samples and their RNA preparations were maintained at $-70{ }^{\circ} \mathrm{C}$ until processed. The all isolates were subjected to CMV subgroup discrimination assays resulting two fragments of 593 and 704 bp, specific to CMV subgroup I and CMV subgroup II, respectively (Chen et al., 2011). Five randomly selected Subgroup I CMV isolates were further characterized by molecular cloning

Before the discrimination subgroup, the cultures of CMV isolates were maintained on $N$. tabacum. Mechanical inoculation was carried out in two cotyledon leaf stages by rub procedure using phosphate buffer $(\mathrm{PB})$, nicotine $(2.5 \%)$ and carborundum powder as an abrasive. The systemically infected test plants kept in 
the climate chamber at room temperature and daylight situations for further investigations. The symptomless tobacco plants were used as a negative control during all experimental processes.

\section{Total RNA extraction, primer design, and cDNA synthesis}

For all specimens, total RNA extractions were performed from about $0.1 \mathrm{~g}$ frozen leaf tissues, following the protocol described by Foissac et al. (2001) with minor modifications. As given in Table 1, specific upstream and downstream primer sets were adopted from previous studies (Nakazono-Nagaoka et al., 2005; Chen et al., 2011), which targeted the CP gen to detect and differentiate CMV SI and SII in tobacco. In all cDNA syntheses, random hexamer primers were used instead of oligo-dT as complementary to mRNA because the CMV nucleic acid was not polyadenylated.

The extracted RNAs were used in the first-strand cDNA synthesis (complementary DNA). In brief, into a nuclease-free microfuge tube, $1 \mu \mathrm{l}$ of random hexamer primer $(20 \mathrm{pmol} / \mu \mathrm{l}), 2 \mu \mathrm{l}$ of extracted RNA as a template and $1 \mu \mathrm{l}$ of dNTP $(10 \mathrm{mM})$ were put then completed to $12 \mu \mathrm{l}$ with nuclease free water. The mixture was held at $65^{\circ} \mathrm{C}$ for $5 \mathrm{~min}$ and chilled on ice.

Four $\mu \mathrm{l}$ of $5 \mathrm{X}$ RT Reaction buffer, $2 \mu \mathrm{l}$ of $0.1 \mathrm{M}$ DTT, $1 \mu \mathrm{l}$ of RNAse inhibitor and $1 \mu \mathrm{l}$ of reverse transcriptase (RT) enzyme (Thermo Scientific, USA) were added to complete the reaction mixture to a final volume of $20 \mu \mathrm{l}$. The reverse transcription reaction was performed at $42^{\circ} \mathrm{C}$ for $50 \mathrm{~min}$. To inactivate the RT enzyme, the mixture was incubated at $70^{\circ} \mathrm{C}$ for $15 \mathrm{~min}$. The cDNAs were maintained at $-20^{\circ} \mathrm{C}$ until processed.

\section{Identification of CMV SI and SII isolates by Multiplex-RT-PCR (M-RT-PCR) assays}

The cDNAs were served as template in M-RT-PCR assay. For CMV SI and SII, the reagents were adjusted empirically in a total volume $50 \mu \mathrm{l}$, consisting of $34.6 \mu \mathrm{l}$ of sterile distilled water, $2 \mu \mathrm{l}$ of cDNA, $3 \mu \mathrm{l}$ of $\mathrm{MgCl}_{2}(25 \mathrm{mM}), 1 \mu \mathrm{l}$ of dNTPs $(10 \mathrm{mM}), 1 \mu \mathrm{l}$ of downstream and upstream primers (20 pmol), $5 \mu \mathrm{l}$ of $10 \mathrm{X}$ Taq buffer, $0.4 \mu \mathrm{l}$ of Taq DNA polymerase $(5 \mathrm{U} / \mu \mathrm{l})$ (Thermo Scientific, USA) enzyme. The temperature cycles of M-RT-PCR reaction were as follows: initial denaturation at $94^{\circ} \mathrm{C}$ for $2 \mathrm{~min}, 35$ cycles of denaturation at 94 ${ }^{\circ} \mathrm{C}$ for 30 s, annealing at $52^{\circ} \mathrm{C}$ for $30 \mathrm{~s}$, elongation at $72{ }^{\circ} \mathrm{C}$ for 45 s. Final elongation occurred at $72{ }^{\circ} \mathrm{C}$ for 10 minutes.

Fifteen $\mu \mathrm{l}$ amplified target fragments were photographed under UV light after electrophoresis on $1.5 \%$ agarose gel containing ethidium bromide $(\mathrm{EtBr})$. Healthy tobacco plants were used as negative control. A CMV SI isolate confirmed by previous sequence analysis was used as positive control.

\section{Cloning, sequencing and cladistic analyses}

Amplified-DNA fragments were separately excised from agarose gel and the amplicons were recovered using GeneJET Gel Extraction Kit (Thermo Scientific, USA) following the manufacturer's instructions. Five randomly selected CMV isolates were cloned into the pGEM T- Easy vector (Promega, USA) following the manufacturer's instructions and transformed into E. coli JM 109 strain. Recombinant plasmids were purified and sequenced bidirectionally in an automated sequencer (Sentebiolab Company, Turkey). Insert sequences were trimmed from raw sequences using CLC Main Workbench program (Version 6.7.1) and recorded to NCBI Database (www.ncbi.nlm.nih.gov).

As presented in Table 2, the cladistic analysis was performed with representative $16 \mathrm{CMV}$ isolates belonging to Subgroup IA, IB, and Subgruop II published in the NCBI. The phylogenetic tree was constructed using Mega 7 program bootstrapped 100 times using the neighbor-joining algorithm (NJA) (Kumar et al., 2016). The nucleic acid sequence alignments were generated using CLC Main Workbench program (Version 6.7.1) to estimate similarity scores. Tomato aspermy virus (EF153735) sequence was used as an outgroup to root the phylogenetic tree. 


\section{Results}

\section{Symptoms produced by CMV isolates}

Symptom development of CMV isolates was examined experimentally. The symptoms developed on $N$. tabacum in experimental studies were similar to the natural diseased $N$. tabacum, but were more evident and severe (Figure 1).
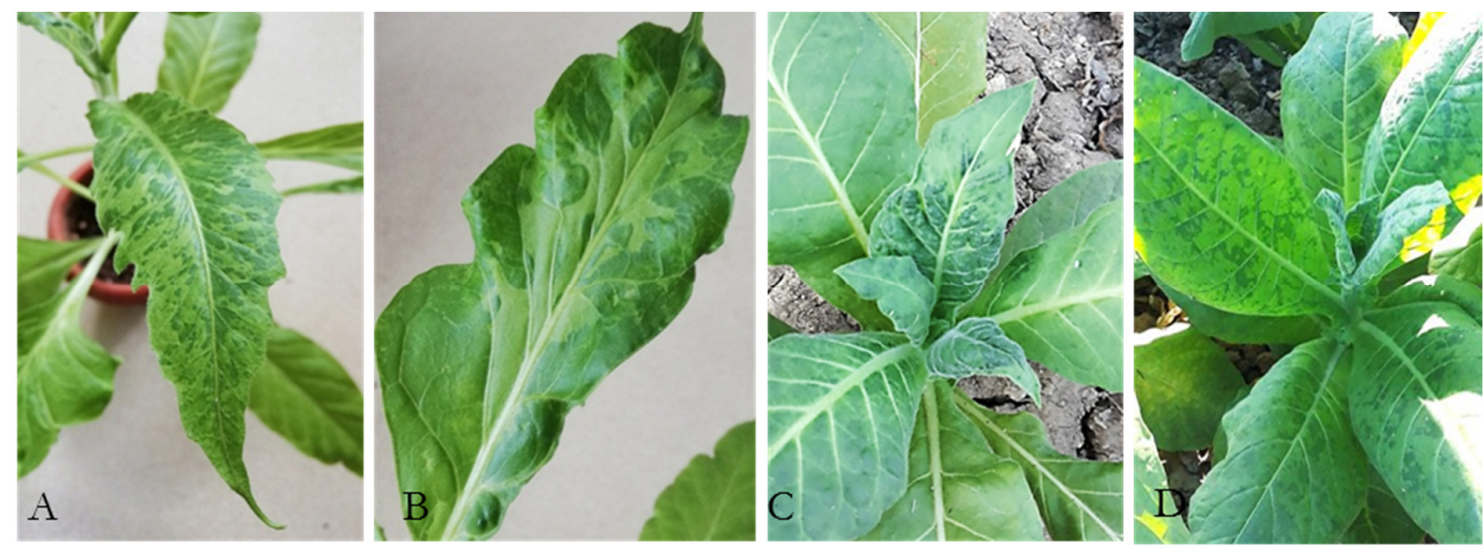

Figure 1. Symptoms of CMV-infected tobacco plants. Panel A and B: Foliar mosaic, leaf puckering in experimental tobacco plants in climate chamber, Panel C and D: Greenish mottle, leaf distortion in field detected tobacco plants

\section{Identification of CMV subgroup I}

Forty samples of nucleic acids were amplified by M-RT-PCR using discrimination primers (Table 1). The resulted amplicons were about $593 \mathrm{bp}$ length indicating that the all isolates were belong to CMV Subgroup I. However, no 704 bp DNA fragments were observed when the Subgroup (SII) primers were used to investigate CMV Subgroup II members (Figure 2).

\section{$B L A S T$ analyses and multiple alignments}

Amplification products of five CMV Subgroup I, representing full length of coat protein gene of (657 bp), were successfully cloned into the pGEM T-Easy vector. The BLAST analyses confirmed the coat protein origin of five cloned sequences. The CMV-Subgroup I tobacco isolates were named TR41, TR54, TR93, TR128, and TR131 and submitted to GenBank with accession numbers of MK89142, MK890143, MK890144, MK890145, and MK890146, respectively. Multiple alignments revealed a high homology between Adiyaman and another Subgroup I isolate in the GenBank. Full-length CP gene sequences of Adiyaman CMV-Subgroup I isolates from tobacco growing region exhibited 94.2 to $100.0 \%$ indentity between five isolates. Multiple sequence alignments indicated that five CMV Subgoup I Adiyaman isolates and the isolates from other geographic origins had 75.1 to $99.7 \%$ identity at the nucleotide level (Table 3).

\section{Cladistic analysis}

Based on molecular relationships and nucleotide sequence similarity, five CMV isolates were classified into two major subgroups. The four isolates (MK890144, MK890146, MK890143, and MK890142) were clustered in SI-A and one isolate (MK890145) in SI-B, fortified by supporting values as shown in Figure 3. 
Table 1. Product size and nucleotide sequences of primers utilized in RT-PCR and M-RT-PCR for detection and discrediting the subgroups of CMV

\begin{tabular}{|c|c|c|c|}
\hline $\begin{array}{c}\text { CMV } \\
\text { primer types }\end{array}$ & Upstream & Downstream & $\begin{array}{c}\text { Amp. } \\
\text { size }\end{array}$ \\
\hline Characterization & ATGGACAAATCTGAATCAAC & TCAGACTGGGAGCACTCCAG & $657 \mathrm{bp}$ \\
\hline Subgroup I $(\mathrm{SI})$ & GCCACCAAAAATAGACCG & ATCTGCTGGCGTGGATTTCT & $593 \mathrm{bp}$ \\
\hline Subgroup $(\mathrm{SII})$ & CTACGTTTATCTTCC & AACCGGTGATTTACCATCGC & $704 \mathrm{bp}$ \\
\hline
\end{tabular}

Table 2. CP gene nucleotide sequences of various CMV strains used for phylogenetic tree

\begin{tabular}{|c|c|c|c|c|c|}
\hline No & Origin & Accession no & Strain names & Subgroup & Host \\
\hline 1 & Hungary & L15336 & $\operatorname{trk} 7$ & SII & - \\
\hline 2 & Australia & M21464 & $Q$ & SII & - \\
\hline 3 & USA & AF127976 & LS & SII & - \\
\hline 4 & Japan & AB006813 & $\mathrm{m} 2$ & SII & - \\
\hline 5 & India & AJ585086 & Indian & SII & Lilium \\
\hline 6 & Australia & U22821 & $\mathrm{Ny}$ & SIA & - \\
\hline 7 & Hungary & AJ517802 & Rs & SIA & Raphanus sativus \\
\hline 8 & Spain & AM183119 & $\mathrm{Ri}-8$ & SIA & Tomato \\
\hline 10 & Israel & U66094 & Sny & SIA & Cucurbita pepo \\
\hline 11 & Italy & Y16926 & Tfn & SIB & Tomato \\
\hline 12 & Taiwan & D28780 & NT9 & SIB & Tomato \\
\hline 13 & USA & D00462 & $\mathrm{C}$ & SIA & - \\
\hline 14 & Japan & D42079 & C7-2 & SIB & - \\
\hline 15 & India & AF281864 & - & SIB & Datura innoxia \\
\hline 16 & Turkey & KY474380 & CWP17 & SIB & Cowpea \\
\hline 17 & India & EF153735 & Kolkata & TAV & $\begin{array}{c}\text { Chrysanthemum } \\
\text { morifolium }\end{array}$ \\
\hline
\end{tabular}

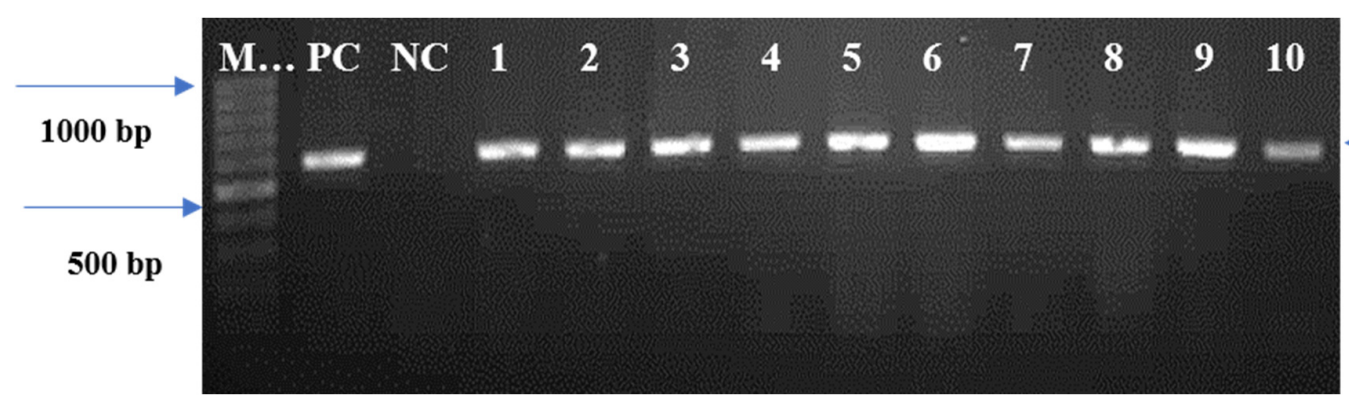

593 bp

Figure 2. Analysis of CMV-Subgroup I from individually infected tobacco plants using multiplex RTPCR; Lane M, 1-kb DNA ladder; PC, Positive control; NC, Negative control; Lane 1-10, CMV Adiyaman isolates 
Table 3. Chart showing multiple alignment analysis of CMV isolates generated with CLC Main Workbench program

\begin{tabular}{|c|c|c|c|c|c|c|c|c|c|c|c|c|c|c|c|c|c|c|c|c|c|c|}
\hline & & 1 & 2 & 3 & 4 & 5 & 6 & 7 & 8 & 9 & 10 & 11 & 12 & 13 & 14 & 15 & 16 & 17 & 18 & 19 & 20 & 21 \\
\hline $\begin{array}{l}\mathrm{U} 6 \\
609 \\
4\end{array}$ & 1 & & $\begin{array}{l}99 . \\
85\end{array}$ & $\begin{array}{l}99 . \\
70\end{array}$ & $\begin{array}{l}99 . \\
54\end{array}$ & $\begin{array}{l}99 . \\
54\end{array}$ & $\begin{array}{l}99 . \\
39\end{array}$ & $\begin{array}{l}99 . \\
24\end{array}$ & $\begin{array}{l}98 . \\
93\end{array}$ & $\begin{array}{l}96 . \\
93\end{array}$ & $\begin{array}{l}95 . \\
43\end{array}$ & $\begin{array}{l}95 . \\
13\end{array}$ & $\begin{array}{l}94 . \\
22\end{array}$ & $\begin{array}{l}94 . \\
22\end{array}$ & $\begin{array}{l}91 . \\
17\end{array}$ & $\begin{array}{l}92 . \\
85\end{array}$ & $\begin{array}{l}81 . \\
43\end{array}$ & $\begin{array}{c}76 . \\
52\end{array}$ & $\begin{array}{l}76 . \\
21\end{array}$ & $\begin{array}{l}76 . \\
36\end{array}$ & $\begin{array}{l}75 . \\
45\end{array}$ & $\begin{array}{c}75 . \\
00\end{array}$ \\
\hline $\begin{array}{l}\mathrm{U} 2 \\
282 \\
1\end{array}$ & 2 & & & $\begin{array}{l}99 . \\
85\end{array}$ & $\begin{array}{l}99 . \\
70\end{array}$ & $\begin{array}{l}99 . \\
70\end{array}$ & $\begin{array}{l}99 . \\
54\end{array}$ & $\begin{array}{l}99 . \\
39\end{array}$ & $\begin{array}{l}99 . \\
09\end{array}$ & $\begin{array}{l}99 . \\
09\end{array}$ & $\begin{array}{l}95 . \\
59\end{array}$ & $\begin{array}{l}95 . \\
28\end{array}$ & $\begin{array}{l}94 . \\
37\end{array}$ & $\begin{array}{l}94 . \\
37\end{array}$ & $\begin{array}{l}91 . \\
32\end{array}$ & $\begin{array}{l}93 . \\
00\end{array}$ & $\begin{array}{l}81 . \\
58\end{array}$ & $\begin{array}{l}76 . \\
67\end{array}$ & $\begin{array}{l}76 \\
36\end{array}$ & $\begin{array}{l}76 . \\
52\end{array}$ & $\begin{array}{l}75 . \\
61\end{array}$ & $\begin{array}{l}75 . \\
00\end{array}$ \\
\hline $\begin{array}{l}\text { AJ } \\
517 \\
802\end{array}$ & 3 & & & & $\begin{array}{l}99 . \\
54\end{array}$ & $\begin{array}{l}99 . \\
54\end{array}$ & $\begin{array}{l}99 . \\
39\end{array}$ & $\begin{array}{l}99 . \\
24\end{array}$ & $\begin{array}{l}98 . \\
93\end{array}$ & $\begin{array}{l}98 . \\
93\end{array}$ & $\begin{array}{l}95 . \\
74\end{array}$ & $\begin{array}{l}95 . \\
43 .\end{array}$ & $\begin{array}{l}94 . \\
52\end{array}$ & $\begin{array}{l}94 . \\
22\end{array}$ & $\begin{array}{l}91 . \\
17\end{array}$ & $\begin{array}{l}93 . \\
15\end{array}$ & $\begin{array}{l}81 . \\
43\end{array}$ & $\begin{array}{l}76 . \\
67\end{array}$ & $\begin{array}{l}76 . \\
36\end{array}$ & $\begin{array}{l}76 . \\
52\end{array}$ & $\begin{array}{l}75 . \\
61\end{array}$ & $\begin{array}{l}75 . \\
00\end{array}$ \\
\hline $\begin{array}{l}\mathrm{A} \\
\mathrm{M} 1 \\
831 \\
19\end{array}$ & 4 & & & & & $\begin{array}{l}99 . \\
39\end{array}$ & $\begin{array}{l}99 . \\
24\end{array}$ & $\begin{array}{l}99 . \\
39 .\end{array}$ & $\begin{array}{l}99 . \\
09\end{array}$ & $\begin{array}{l}99 . \\
09\end{array}$ & $\begin{array}{l}95 . \\
28 .\end{array}$ & $\begin{array}{l}94 . \\
98\end{array}$ & $\begin{array}{l}94 . \\
67\end{array}$ & $\begin{array}{l}94 . \\
22\end{array}$ & $\begin{array}{l}91 . \\
32\end{array}$ & $\begin{array}{l}93 . \\
69\end{array}$ & $\begin{array}{l}81 . \\
43\end{array}$ & $\begin{array}{l}76 . \\
82\end{array}$ & $\begin{array}{l}76 . \\
52\end{array}$ & $\begin{array}{l}76 . \\
67\end{array}$ & $\begin{array}{l}75 . \\
76\end{array}$ & $\begin{array}{l}75 . \\
15\end{array}$ \\
\hline $\begin{array}{l}\mathrm{M} \\
\mathrm{K} 8 \\
901 \\
44\end{array}$ & 5 & & & & & & $\begin{array}{l}99 . \\
24\end{array}$ & $\begin{array}{l}99 . \\
39\end{array}$ & $\begin{array}{l}99 . \\
09\end{array}$ & $\begin{array}{l}99 . \\
09\end{array}$ & $\begin{array}{l}95 . \\
59\end{array}$ & $\begin{array}{l}95 . \\
28\end{array}$ & $\begin{array}{l}94 . \\
06\end{array}$ & $\begin{array}{l}94 . \\
37\end{array}$ & $\begin{array}{l}91 . \\
32\end{array}$ & $\begin{array}{l}93 . \\
00\end{array}$ & $\begin{array}{l}81 . \\
43\end{array}$ & $\begin{array}{l}76 . \\
97\end{array}$ & $\begin{array}{l}76 . \\
67\end{array}$ & $\begin{array}{l}76 . \\
82\end{array}$ & $\begin{array}{l}75 . \\
91\end{array}$ & $\begin{array}{l}75 . \\
30\end{array}$ \\
\hline $\begin{array}{l}\text { D0 } \\
046 \\
2\end{array}$ & 6 & & & & & & & $\begin{array}{l}98 . \\
93\end{array}$ & $\begin{array}{l}98 . \\
63\end{array}$ & $\begin{array}{l}98 . \\
63\end{array}$ & $\begin{array}{l}95 . \\
13 .\end{array}$ & $\begin{array}{l}94 . \\
82\end{array}$ & $\begin{array}{l}93 . \\
91\end{array}$ & $\begin{array}{l}93 . \\
91\end{array}$ & $\begin{array}{l}90 . \\
87\end{array}$ & $\begin{array}{l}92 . \\
54\end{array}$ & $\begin{array}{l}81 . \\
13\end{array}$ & $\begin{array}{l}76 . \\
21\end{array}$ & $\begin{array}{l}76 . \\
91\end{array}$ & $\begin{array}{l}76 . \\
06\end{array}$ & $\begin{array}{l}75 . \\
15\end{array}$ & $\begin{array}{l}75 . \\
55\end{array}$ \\
\hline $\begin{array}{l}\mathrm{M} \\
\mathrm{K} 8 \\
901 \\
46\end{array}$ & 7 & & & & & & & & $\begin{array}{l}99 . \\
09\end{array}$ & $\begin{array}{l}99 . \\
09\end{array}$ & $\begin{array}{l}94 . \\
98\end{array}$ & $\begin{array}{l}95 . \\
13 .\end{array}$ & $\begin{array}{l}94 . \\
06\end{array}$ & $\begin{array}{l}94 . \\
22\end{array}$ & $\begin{array}{l}91 . \\
48\end{array}$ & $\begin{array}{l}93 . \\
00\end{array}$ & $\begin{array}{l}81 . \\
28\end{array}$ & $\begin{array}{l}76 . \\
82\end{array}$ & $\begin{array}{l}76 . \\
52\end{array}$ & $\begin{array}{l}76 . \\
67\end{array}$ & $\begin{array}{l}75 . \\
76\end{array}$ & $\begin{array}{l}75 . \\
15\end{array}$ \\
\hline $\begin{array}{l}\mathrm{M} \\
\mathrm{K} 8 \\
901 \\
42\end{array}$ & 8 & & & & & & & & & 100 & $\begin{array}{l}94 . \\
98\end{array}$ & $\begin{array}{l}94 . \\
98\end{array}$ & $\begin{array}{l}93 . \\
76\end{array}$ & $\begin{array}{l}94 . \\
52\end{array}$ & $\begin{array}{l}91 . \\
32\end{array}$ & $\begin{array}{l}93 . \\
30\end{array}$ & $\begin{array}{l}81 . \\
74\end{array}$ & $\begin{array}{l}76 . \\
97\end{array}$ & $\begin{array}{l}76 . \\
67\end{array}$ & $\begin{array}{l}76 . \\
82\end{array}$ & $\begin{array}{l}75 . \\
91\end{array}$ & $\begin{array}{l}75 . \\
30\end{array}$ \\
\hline $\begin{array}{l}\mathrm{M} \\
\mathrm{K} 8 \\
901 \\
43\end{array}$ & 9 & & & & & & & & & & $\begin{array}{l}99 . \\
70\end{array}$ & $\begin{array}{l}94 . \\
98\end{array}$ & $\begin{array}{l}93 . \\
76\end{array}$ & $\begin{array}{l}94 . \\
52\end{array}$ & $\begin{array}{l}91 . \\
32\end{array}$ & $\begin{array}{l}93 . \\
30\end{array}$ & $\begin{array}{l}81 . \\
74\end{array}$ & $\begin{array}{l}76 . \\
97\end{array}$ & $\begin{array}{l}76 . \\
67\end{array}$ & $\begin{array}{l}76 . \\
82\end{array}$ & $\begin{array}{c}75 . \\
91\end{array}$ & $\begin{array}{l}75 . \\
30\end{array}$ \\
\hline $\begin{array}{l}\mathrm{Y} 1 \\
692 \\
6\end{array}$ & 10 & & & & & & & & & & & $\begin{array}{l}99 . \\
70 .\end{array}$ & $\begin{array}{l}94 . \\
98\end{array}$ & $\begin{array}{l}93 . \\
61\end{array}$ & $\begin{array}{l}92 . \\
85\end{array}$ & $\begin{array}{l}93 . \\
76\end{array}$ & $\begin{array}{l}82 . \\
65\end{array}$ & $\begin{array}{l}77 . \\
88\end{array}$ & $\begin{array}{l}77 . \\
58\end{array}$ & $\begin{array}{l}77 . \\
73\end{array}$ & $\begin{array}{l}76 . \\
82\end{array}$ & $\begin{array}{l}76 . \\
21\end{array}$ \\
\hline $\begin{array}{l}\text { D2 } \\
878 \\
0\end{array}$ & 11 & & & & & & & & & & & & $\begin{array}{l}94 . \\
98\end{array}$ & $\begin{array}{l}93 . \\
30\end{array}$ & $\begin{array}{l}92 . \\
54\end{array}$ & $\begin{array}{l}93 . \\
76\end{array}$ & $\begin{array}{l}82 . \\
34\end{array}$ & $\begin{array}{l}77 . \\
58\end{array}$ & $\begin{array}{l}77 . \\
27\end{array}$ & $\begin{array}{l}77 . \\
42\end{array}$ & $\begin{array}{l}76 . \\
52\end{array}$ & $\begin{array}{l}75 . \\
91\end{array}$ \\
\hline $\begin{array}{l}\mathrm{D} 4 \\
207 \\
9\end{array}$ & 12 & & & & & & & & & & & & & $\begin{array}{l}93 . \\
30\end{array}$ & $\begin{array}{l}91 . \\
78\end{array}$ & $\begin{array}{l}92 . \\
54\end{array}$ & $\begin{array}{l}81 . \\
28\end{array}$ & $\begin{array}{l}76 . \\
97\end{array}$ & $\begin{array}{l}76 . \\
67\end{array}$ & $\begin{array}{l}76 . \\
82\end{array}$ & $\begin{array}{l}75 . \\
91\end{array}$ & $\begin{array}{l}75 . \\
30\end{array}$ \\
\hline $\begin{array}{l}\mathrm{M} \\
\mathrm{K} 8 \\
901 \\
45\end{array}$ & 13 & & & & & & & & & & & & & & $\begin{array}{l}94 . \\
06\end{array}$ & $\begin{array}{l}93 . \\
15\end{array}$ & $\begin{array}{l}84 . \\
17\end{array}$ & $\begin{array}{l}76 . \\
82\end{array}$ & $\begin{array}{l}76 . \\
52\end{array}$ & $\begin{array}{l}76 . \\
67\end{array}$ & $\begin{array}{l}75 . \\
76\end{array}$ & $\begin{array}{l}75 . \\
15\end{array}$ \\
\hline $\begin{array}{l}\text { AF } \\
281 \\
864\end{array}$ & 14 & & & & & & & & & & & & & & & $\begin{array}{l}92 . \\
39\end{array}$ & $\begin{array}{l}82 . \\
19\end{array}$ & $\begin{array}{l}76 . \\
30\end{array}$ & $\begin{array}{l}75 . \\
00\end{array}$ & $\begin{array}{l}75 . \\
15\end{array}$ & $\begin{array}{l}74 . \\
24\end{array}$ & $\begin{array}{l}75 . \\
94\end{array}$ \\
\hline $\begin{array}{l}\text { AJ } \\
271 \\
416\end{array}$ & 15 & & & & & & & & & & & & & & & & $\begin{array}{l}80 . \\
97\end{array}$ & $\begin{array}{l}76 . \\
82\end{array}$ & $\begin{array}{l}76 . \\
52\end{array}$ & $\begin{array}{l}76 . \\
67\end{array}$ & $\begin{array}{l}75 . \\
76\end{array}$ & $\begin{array}{l}75 . \\
45\end{array}$ \\
\hline $\begin{array}{l}\mathrm{KY} \\
474 \\
380\end{array}$ & 16 & & & & & & & & & & & & & & & & & $\begin{array}{l}67 . \\
58\end{array}$ & $\begin{array}{l}67 . \\
27\end{array}$ & $\begin{array}{l}67 . \\
42\end{array}$ & $\begin{array}{l}66 . \\
52\end{array}$ & $\begin{array}{l}66 . \\
21\end{array}$ \\
\hline $\begin{array}{l}\text { M2 } \\
146 \\
4\end{array}$ & 17 & & & & & & & & & & & & & & & & & & $\begin{array}{l}99 . \\
54 .\end{array}$ & $\begin{array}{l}99 . \\
39\end{array}$ & $\begin{array}{l}98 . \\
63\end{array}$ & $\begin{array}{l}97 . \\
72\end{array}$ \\
\hline $\begin{array}{l}\text { AF } \\
127 \\
976\end{array}$ & 18 & & & & & & & & & & & & & & & & & & & $\begin{array}{l}99 . \\
54\end{array}$ & $\begin{array}{l}98 . \\
78\end{array}$ & $\begin{array}{l}98 . \\
17\end{array}$ \\
\hline $\begin{array}{l}\mathrm{AB} \\
006 \\
813\end{array}$ & 19 & & & & & & & & & & & & & & & & & & & & $\begin{array}{l}98 . \\
78\end{array}$ & $\begin{array}{l}97 . \\
72\end{array}$ \\
\hline $\begin{array}{l}\text { L1 } \\
533 \\
6\end{array}$ & 20 & & & & & & & & & & & & & & & & & & & & & $\begin{array}{l}96 . \\
96\end{array}$ \\
\hline $\begin{array}{l}\text { AJ } \\
585 \\
086\end{array}$ & 21 & & & & & & & & & & & & & & & & & & & & & \\
\hline
\end{tabular}




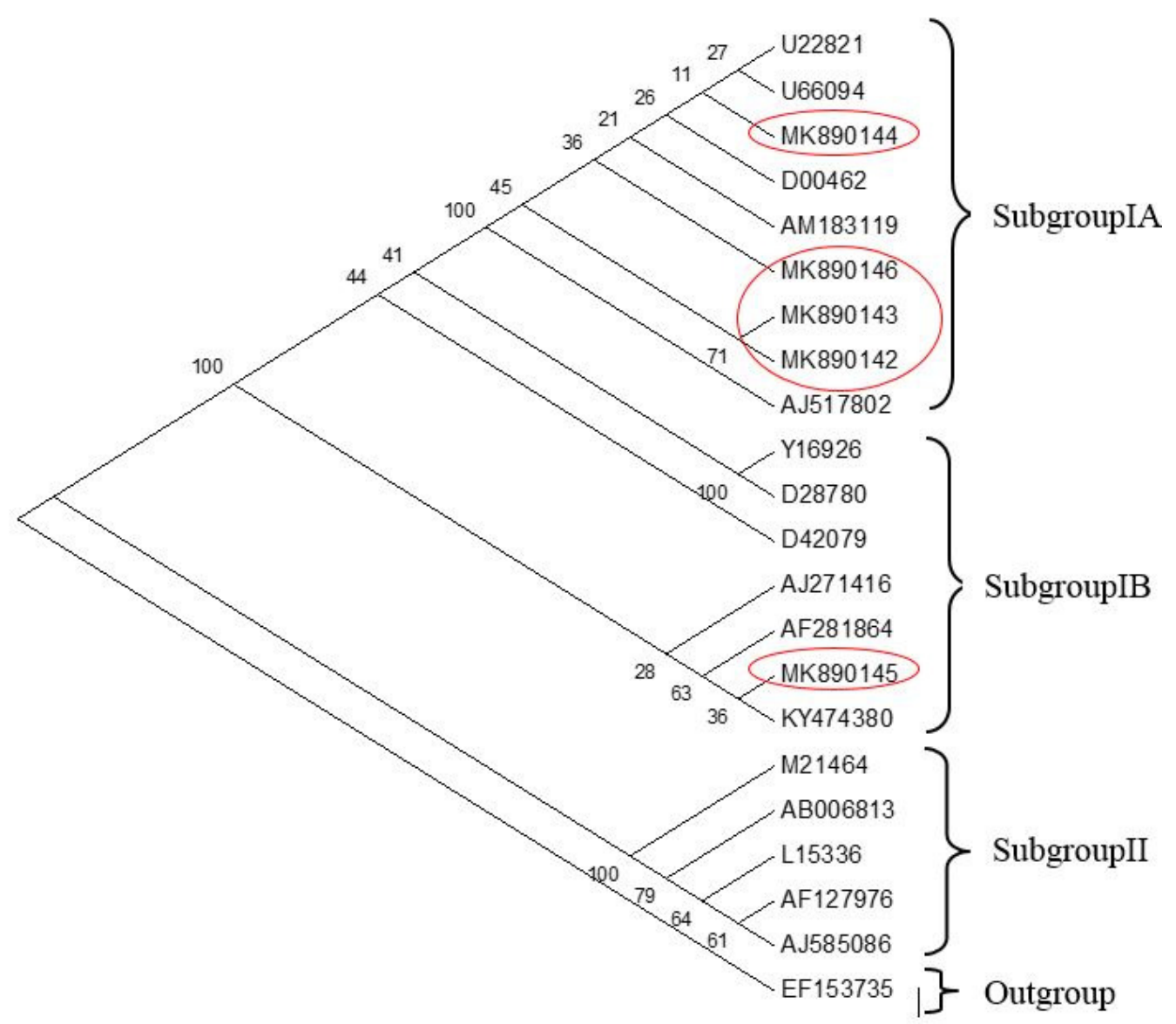

Figure 3. Phylogenetic dendrogram constructed with CMV-Adiyaman isolates and the isolates, retrieved from GenBank, created by the neighbour-joining algorithm. The sequence of tomato aspermy virus isolate (EF153735) was used as an outgroup to root the tree. Bootstrap values are shown on each branch

\section{Discussion}

Identification of CMV isolates is important to elucidate the ancestor of this virus and develop a control strategy. Although ELISA and RFLP assays are used (Haase et al., 1989; Shevchenko et al., 2015), Multiplex RT-PCR is a practical method for the simultaneous differentiation of CMV subgroup I and II (Rizos et al., 1992; Yu et al., 2005; Eyvazi et al., 2015). To differentiate CMV subgroups, various primers have been developed by various researchers based on the conserved sequence within the viral genomic segment. Primers used by Chen et al. (2011) produced 593 bp amplicons in RT-PCR tests, consistent with the present study.

SI-A, SI-B and SII groups of CMV have been reported in literature from numerous countries such as USA (D10538, IA), Japan (D16405, IA), South Korea (AJ27648, IA), Indonesia (AB042294, IB), Philippines (U20219, IB), Spain (AM183119, IA), Taiwan (D28780, IB), Italy (Y16926, IB), USA (AF127976, II), Australia (AF198103, II), South Africa (U37227, II), and Hungary (L15336, II) (Rodríguez Pardina et al., 2013; Arafati et al., 2013). Furthermore, historical records denoted that S-IA members were distributed throughout the world, while SI-B members were mostly reported in eastern Asia, considered to be the origin of this subgroup, although some have been found in Mediterranean region, Iran, California, Brazil, Australia and Greece (Sclavounos et al., 2006; Farzadfar et al., 2013). In this study, it was determined that one isolate classified in CMV SI-B and the others (four isolates) were in CMV SI-A based on the phylogenetic assay. None 
of the isolates was classified in CMV subgroup II. The widespread of CMV subgroup I isolates in this region may be due to its severity and abundancy worldwide, compatible with previous reports (Singh et al., 1995; Tian et al., 2009). The absence of CMV SII isolates in our tests could probably be explained by inappropriate climate conditions in the surveyed areas and probably because of its tropical climate's adoption (Hord et al., 2001; Kumari et al., 2013).

CMV SI isolates have been perfectly adapted to various plants such as cucumber, tomato, pepper, tobacco, pumpkin, bean, celery, musa crops, peanut, yam, and weeds from different locations in world, confirmed by serological and molecular tests (Eni et al., 2013; Ayo-John and Hughes, 2014; Zhu et al., 2018). The presence of CMV in tobacco has been reported by several researchers as both natural hosts (Chatzivassiliou et al., 2004; Dai et al., 2012; Zhang et al., 2013) and experimental host (Tian et al., 2009; Chikh Ali et al., 2012). It has a nationwide host range with the exception of tobacco, which includes: Myrtle leaf milkwort, globe artichoke, parsley, mint, broccoli, squash, olives, cabbage, peppers, lettuce, spinach, cowpea, gladiolus, tomatoes, zucchini, cucumber, ornamental plants (daffodils, hyacinths, lilies), bean and spinach (Gümüs et al., 2004; Beler and Acıkgöz, 2005; Sevik and Akcura, 2011; Culal Kılıc and Yardımc1, 2012; Erkan et al., 2013; Ergün et al., 2013; Culal K1lıc et al., 2015; Uzunoğulları and Gümüs, 2015; Sertkaya, 2015; Karanfil et al., 2016; Gökdag et al., 2016; Güngör et al., 2017; Karanfil and Korkmaz, 2017; Koc and Fidan, 2017; Sevik, 2012, 2017). Since its transmission to tobacco is not seed-borne (De Bokx and Huttinga, 1981), its presence and prevalence can stem from other virus sources like weeds, the suitable climate environment for active aphid populations throughout tobacco production season and acquired from other cultivated plants grown from CMV- infected seeds (Kaplan et al., 1997; Tsitsipis et al., 2001).

CMV exhibited characteristic symptoms more severely such as mottle, mosaic and leaf malformation in experimental transmission studies on tobacco. These symptoms were similar to those mentioned by Chikh Ali et al. (2012), Sclavounos et al. (2006) and Arafati et al. (2013) on tobacco leaves and on many hosts both native flora and experimental studies (Zhang et al., 1994; Jalender et al., 2017).

Analysis of phylogenetic tree showed that Turkish tobacco SI-A isolates (MK89142, MK890143, MK890144, MK890146) were clustered in the same branch, and well differentiated from the members of SIB isolates. Within SI-A, one isolate (MK890144) was closely related to the Israelli-squash (U66094) isolate, one isolate (MK890146) was related to the Spanish-tomato (AM183119) isolate, the other two isolates (MK890142 and MK890143) were closely related to each other, which formed a separate cluster. The Adiyaman SI-B isolate (MK890145) was phylogenetically grouped with the Turkish cowpea SI-B isolate (KY474380). Multiple alignments further revealed that the sequence of CP of CMV SI-B isolate showed approximately $94 \%$ sequence similarity, whereas CMV SI-A isolates shared the maximum identity of $94.22-$ $100 \%$ among themselves at the $\mathrm{CP}$ gene level (Table 2). These incidences coincide with the literature reported by Palukaitis and Garcia-Arenal, (2003). The highest homology (100\%) was shared between MK890142 and MK890143 isolates (subgroup I-A), while the lowest homology (94.22\%) was shared between MK890146 (subgroup I-A) and MK890145 (subgroup I-B) isolates. This variation among CMV I isolates can likely be due to reassortment occurring within the $\mathrm{CP}$ gene demonstrating the event of new strains due to proceeding evolvement (Moury, 2004).

Based on previous studies carried out in Turkey, CMV SI-A has been found in pepper, tomato and watermelon (Caglar, 2006), CMV SI and SII in pepper, tomato, cucumber, watermelon and melon (Sar1, 2015), CMV SI-B in cowpea (Karanfil and Korkmaz, 2017) and, CMV SI-A in spinach (Kurtoglu and Korkmaz, 2018). Even though CMV has been detected on a wide range of hosts in Turkey, subgroup categories and their classification of most of them were not currently completed at the nucleotide levels. Further molecular analyses are needed for classifying the CMV isolates into subgroups on diverse crops. The present study is the first report on the presence of CMV subgroup I-A and I-B in infected tobacco and their molecular characterizations in cultured tobaccos in Adiyaman province. 


\section{Acknowledgements}

The study was supported by a grant from The Research Fund of Van Yüzüncü Yil University-YYUBAP (Project no: FYL-2018-7339). The authors acknowledge YYU-BAP for their financial supports.

\section{Conflict of Interests}

The authors declare that there are no conflicts of interest related to this article.

\section{References}

Akinyemi IA, Wang F, Zhou B, Qi S, Wu Q (2016). Eco-genomic survey of plant viruses infecting tobacco by next generation sequencing. Virology Journal 13:181. https://doi.org/10.1186/s12985-016-0639-7

Arafati N, Farzadfar S, Pourrahim R (2013). Characterization of coat protein gene of cucumber mosaic virus isolates in Iran. Iranian Journal of Biotechnology 1(2):109-114. https://doi.org/10.5812/ijb.10715

Ayo-John EI, Hughes Jd'A (2014). Identification of cucumber mosaic virus (CMV) isolates infecting Musa spp. and vegetable crops in Southern Nigeria. International Journal of Virology 10:204-210. https://doi.org/10.3923/ijv.2014.204.210

Ayo-John EI, Hughes DJA, Ekpo EJA (2008). Survey for CMV in field samples of Musa spp. in southern Nigeria. International Journal of Pest Management 54:167-172. https://doi.org/10.1080/09670870701875235

Beler Ö, Acıkgöz S (2005). Detection of some virus diseases in olive trees and trees in Aegean and Marmara regions by ELISA test. ADU Journal of Faculty of Agriculture 2(1):79-84.

Chatzivassiliou EK (2008). Management of the spread of tomato spotted wilt virus in tobacco crops with insecticides based on estimates of trips infestation and virus incidence. Plant Disease 92:1012-1020. https://doi.org/10.1094/PDIS-92-7-1012

Chen S, Gu H, Wang X, Chen J, Zhu W (2011). Multiplex RT-PCR detection of Cucumber mosaic virus subgroups and Tobamoviruses infecting tomato using $18 \mathrm{~S} \mathrm{rRNA}$ as an internal control. Acta Biochimica et Biophysica Sinica 43:465-471. https://doi.org/10.1093/abbs/gmr031

Chen W, Dai J, Zhang H, Jiao H, Cheng J, Wu Y (2014). Concentration and detection of tobacco etch virus from irrigation water using real-time PCR. Turkish Journal of Agriculture and Forestry 38:471-477. https://doi.org/10.3906/tar-1305-98

Chikh Ali M, Omar AMS, Maoka T, Natsuaki KT, Natsuaki T (2012). Characterization of potato and tobacco isolates of cucumber mosaic virus from Syria and the first report on CMV satellite RNA from potato. Phytopathologia Mediterranea 51(1):3-10.

Caglar BK (2006). Characterization of isolates of cucumber mosaic virus in melon, tomato and pepper by biological, serological and molecular methods and their effect on the virus of satellite RNAs. PhD Thesis, Cukurova University, Adana, Turkey.

Culal Kılıc H, Yardımcı N (2012). Cucumber mosaic virus in çine plain bean fields in Burdur province. Mehmet Akif Ersoy University, Journal of the Institute of Science and Technology 3(2):12-15.

Culal Kılıc H, Yardımcı N, Toplu S, Konu A (2015). Cucumber mosaic virus and pepper mild mottle virus in pepper growing areas in Burdur province, Turkey. International Journal of Scientific and Technological Research 1:1.

Dai J, Cheng J, Huang T, Zheng X, Wu Y (2012). A multiplex reverse transcription PCR assay for simultaneous detection of five tobacco viruses in tobacco plants. Journal of Virological Methods 183:57-62. https://doi.org/10.1016/j.jviromet.2012.03.029

De Bokx JA, Huttinga H (1981). Potato virus Y. CMI/AAB Descriptions of Plant Viruses 242:6.

Doolittle SP (1916). A new infectious mosaic disease of cucumber. Phytopathology 6:145-147.

Eni AO, Lava Kumar P, Asiedu R, Alabi OJ, Naidu RA, Rey MEC (2013). Characterization of cucumber mosaic virus isolated from yam (Dioscorea spp.) in West Africa. African Journal of Biotechnology 12(22):3472-3480. https://doi.org/10.1094/pdis-92-5-0833b 
EPPO/CABI (1996b). Tomato ringspot nepovirus. In: Quarantine pests for Europe. $2^{\text {nd }}$ edition (Ed. by Smith IM, McNamara DG, Scott PR, Holderness M). Cab International, Wallingford, UK.

Ergün M, Semih E, Paylan IC (2013). Cucumber mosaic virus in globe artichoke in Turkey. Canadian Journal of Plant Pathology 35(4):514-517. https://doi.org/10.1080/07060661.2013.833987

Erkan S, Gümüs M, Paylan IC, Duman I, Ergün M (2013). Determination of viral factors in some winter vegetables in İzmir province and its surroundings. Ege University Journal of Faculty of Agriculture 50(3):311-322.

Eyvazi A, Dizadji A, Rastgou M, Koohi Habibi M (2015). Bioassay and phylogeny of five Iranian isolates of cucumber mosaic virus from different hosts based on CP gene sequence. Plant Protection Science 51(4):200-207. https://doi.org/10.17221/80/2014-pps

FAO (2013). United Nations Food and Agriculture Organization Agricultural Statistics. Retrieved 2013 March 24 from http://faostat.fao.org/

Farzadfar S, Pourrahim R, Arafati N (2013). Molecular identification of cucumber mosaic virus subgroup IB isolates in South Iran. Journal of Plant Pathology 95(2):423-428.

Foissac L, Gentit P, Svanetia-Dumas L, Dulucq MJ, Candresse T (2001). Polyvalent detection of fruit tree tricho, capillo, and foveaviruses by nested RT-PCR using degenerated and inosine-containing primers (PDO RT-PCR). Acta Horticulturae 550:37-43. https://doi.org/10.17660/actahortic.2001.550.2

Garcia-Arenal F, Palukaitis P (2008). Cucumber mosaic virus. In: BWJ Mahy and MHV van Regenmortel (Eds.). Desk encyclopedia of plant and fungal virology. Elsevier Amsterdam pp 171-176.

Gökdag S, Karanfil A, Korkmaz S (2016). Determination of turnip mosaic virus and cucumber mosaic virus in Canakkale spinach fields. In: Garden special issue (VII). National Horticultural Congress Proceedings (2): VegetableViticulture-Ornamental Plants pp 166-170.

Gümüs M, Erkan S, Tok S (2004). Research on the detection of viral factors in the seeds of some cucurbit species. Journal of Ege University Faculty of Agriculture 41(1):49-56.

Güngör M, Uzunbacak H, Kutluk-Yilmaz ND, Sevik MA (2017). Identification of viruses that cause infection in spinach production areas of Samsun province. Anadolu Journal of Agricultural Sciences 32:164-168.

Günay A (2019). Investigation of some tobacco viruses by multiplex RT-PCR method in Adiyaman province tobacco production fields and molecular characterization of some virus isolates. MSc Dissertation, Van Yuzuncu Yil University.

Haase A, Richter J, Rabenstein F (1989). Monoclonal antibodies for detection and serotyping of cucumber mosaic virus. Phytopathology 127:129-136. https://doi.org/10.1111/j.1439-0434.1989.tb01121.x

Hord MJ, Garcia A, Villalobos H, Rivera C, Macaya G (2001). Field survey of Cucumber mosaic virus subgroups I and II in crop plants in Costa Rica. Plant Disease 85:952-954. https://doi.org/10.1094/PDIS.2001.85.9.952

Jalender P, Bhat BN, Anitha K., Vijayalakshmi K (2017). Studies on transmission of cucumber mosaic virus (CMV) by sap inoculation in tomato. International Journal of Pure and Applied Bioscience 5(4):1908-1912. https://doi.org/10.18782/2320-7051.5764

Jaspars EMJ, Bos L (1980). Alfalfa mosaic virus. CMI/AAB Descriptions of Plant Viruses 229:7.

Kaplan IB, Gal-On A, Palukaitis P (1997). Characterization of cucumber mosaic virus. III. Localization of sequences in the movement protein controlling systemic infection in cucurbits. Virology 230:343-349. https://doi.org/10.1006/viro.1997.8468

Karanfil A, Korkmaz S (2017). Detection of cucumber mosaic virus (Cucumber mosaic virus; CMV) in the cowpea production areas of Çanakkale province and its molecular characterization. Plant Protection Bulletin 57(3):293304. https://doi.org/10.16955/bitkorb.340046

Karanfil A, Soylu B, Korkmaz S (2016). Investigation of cucumber mosaic virus infection in bulbous ornamental plants by serological and molecular methods in Çanakkale province and its districts. Trakya University Journal of Natural Sciences 17(2):105-110.

Koc G, Fidan H (2017). In Turkey, cucumber mosaic virus (CMV) for a host of evergreens: Polygala myrtifolia. Derim 34(1):29-36. https://doi.org/10.16882/derim.2017.305281

Kumar S, Stecher G, Tamura, K (2016). MEGA7: Molecular Evolutionary Genetics Analysis version 7.0 for bigger datasets. Molecular Biology and Evolution 33:1870-1874. https://doi.org/10.1093/molbev/msw054

Kumari R, Bhardwaj P, Singh L, Zaidi AA, Hallan V (2013). Biological and molecular characterization of cucumber mosaic virus subgroup II isolate causing severe mosaic in cucumber. Indian Journal of Virology 24(1):27-34. https://doi.org/10.1007/s13337-012-0125-9 
Kurtoglu A, Korkmaz S (2018). Determination and molecular characterization of cucumber mosaic virus (CMV) infection on spinach production fields of Çanakkale province, Turkey. The Journal of Turkish Phytopathology 47(2):43-51.

Lin HX, Rubio L, Smythe A, Jiminez M, Falk BW (2003). Genetic diversity and biological variation among California isolates of cucumber mosaic virus. Journal of General Virology 84:249-258. https://doi.org/10.1099/vir.0.18673-0

Moury B (2004). Differential selection of genes of cucumber mosaic virus subgroups. Molecular Biology and Evolution 21:1602-1611. https://doi.org/10.1093/molbev/msh164

Nagendran K, Priyanka R, Aravintharaj R, Balaji CG, Swamy Prashant, Bagewadi Basavaraj, ... Karthikeyan G (2018). Characterization of cucumber mosaic virus infecting snake gourd and bottle gourd in India. Physiological and Molecular Plant Pathology 103:102-106. https://doi.org/10.1016/j.pmpp.2018.05.010

Nakazono-Nagaoka E, Suzuki M, Kosaka Y, Natsuaki T (2005). RT-PCR-RFLP analysis for evaluating cross protection by an attenuated isolate of cucumber mosaic virus. Journal of General Plant Pathology 71(3):243-246. https://doi.org/10.1007/s10327-005-0192-5

Özdag Y, Sertkaya G (2017). Investigation on viruses causing yellowing disease in pepper in Hatay-Turkey. Journal of Agricultural Faculty of Mustafa Kemal University 22(1):16-22.

Palukaitis P, Garcia-Arenal F (2003). Cucumber mosaic virus. AAB Descriptions of Plant Viruses 400.

Palukaitis P, Roossinck MJ, Dietzgen RG, Francki RI (1992). Cucumber mosaic virus. Advances in Virus Research 41:281348. https://doi.org/10.1016/s0065-3527(08)60039-1

Park TS, You JW, Park JS, Jeong RD, Hong JS (2018). First report of cucumber mosaic virus infecting Solanum pseudocapsicum in Korea. Journal of Plant Pathology 100:147. https://doi.org/10.1007/s42161-018-0037-7

Rizos H, Gunn LV, Pares RD, Gillings RM (1992). Differentiation of cucumber mosaic virus isolates using the polymerase chain reaction. Journal of General Virology 73:2099-2103. https://doi.org/10.1099/0022-1317-73-8-2099

Rodríguez Pardina P, Ojeda M, Biderbost E, Di Feo L (2013). Detection and characterization of a cucumber mosaic virus isolate infecting peperina, a species native to Argentina. Agriscientia 30(2):79-85. https://doi.org/10.31047/1668.298x.v30.n2.8993

Roossinck MJ (2002). Evolutionary history of cucumber mosaic virus deduced by phylogenetic analyses. Journal of Virology. 76:3382-3387. https://doi.org/10.1128/jvi.76.7.3382-3387.2002

Sar1 S (2015). Characterization of cucumber mosaic virus (CMV) isolates causing infection in summer vegetables grown in Samsun province and investigation of host-simptom-satellite RNA relationships. MSc Dissertation, Ondokuz Mayıs University.

Sclavounos AP, Voloudakis AE, Arabatzis C, Kyriakopoulou PE (2006). A severe Hellenic CMV tomato isolate: symptom variability in tobacco, characterization and discrimination of variants. European Journal of Plant Pathology 115:163-172. https://doi.org/10.1007/s10658-006-0010-8

Sertkaya G (2015). Investigation of some viruses in the areas of lettuce and spinach in Hatay province. Mustafa Kemal University Journal of the Faculty of Agriculture 20(1):7-12.

Sevik MA (2012). Natural occurrence of cucumber mosaic virus infecting water mint (Mentha aquatica) in Antalya and Konya, Turkey. The Journal Acta Botanica Croatica 71(1):187-193. https://doi.org/10.2478/v10184-011-0052-7

Sevik MA (2017). Natural occurrence of cucumber mosaic virus infecting broccoli in Turkey. Virus Disease 28(2):218219. https://doi.org/10.1007/s13337-017-0373-9

Sevik MA, Akcura C (2011). Occurrence of cucumber mosaic virus infecting parsley (Petroselinum crispum) in Turkey. Notulae Botanicae Horti Agrobotanici Cluj-Napoca 39(1):30-33. https://doi.org/10.15835/nbha3915598

Shevchenko TP, Tymchyshyn OV, AlDalain E, Bysov AS, Budzanivska IG, Shevchenko OV, Polishchuk VP (2015). The first evidence of subgroup IB isolates of cucumber mosaic virus in Ukraine. Biopolymers and Cell 31(1):57-62. https://doi.org/10.7124/bc.0008cd

Singh Z, Jones RAC, Jones MGK (1995). Identification of cucumber mosaic virus subgroup I isolates from banana plants affected by infectious chlorosis disease using RT-PCR. Plant Disease 79:713-716. https://doi.org/10.1094/pd-790713

Tian Z, Qiu J, Yu J, Han C, Liu W (2009). Competition between cucumber mosaic virus subgroup I and II isolates in tobacco. Journal of Phytopathology 157:457-464. https://doi.org/10.1111/j.1439-0434.2008.01531.x 
Tsitsipis JA, Gargalianou I, Eythimiou K, Chatzivassiliou EK, Katis NI (2001). Aphid population fluctuation and spread of potato virus Y (PVY) and cucumber mosaic virus (CMV) in tobacco crops in Greece and Italy. Abstracts, $6^{\text {th }}$ International Symposium on Aphids. Aphids in a New Millennium. Rennes, France pp 169.

TUIK (2015). Turkey Statistical Institute (TUIK). Retrieved 2017 February 10 from https://biruni.tuik.gov.tr/bitkiselapp/bitkisel.zul

Uzunogulları N, Gümüs M (2015). Detection of cucumber mosaic virus (CMV) causing natural infection in some cultivated plants in the Marmara Region. Trakya University Journal of Natural Sciences 16(1):9-15.

Valand GB, Muniyappa V (1992). Epidemiology of tobacco leaf curl virus in India. Annals of Applied Biology 120(2):257267. https://doi.org/10.1111/j.1744-7348.1992.tb03423.x

Yardımcı N, Culal Kılıc H, Kör A (2015). Identification of cucumber mosaic virus (CMV) on Squash (Cucurbita pepo L.) cultivars in Lakes region of Turkey. Fresenius Environmental Bulletin 24:2.

Yu C, Wu J, Zhou X (2005). Detection and subgrouping of cucumber mosaic virus isolates by TAS-ELISA and immunocapture RT-PCR. Journal of Virological Methods 123:155-161. https://doi.org/10.1016/j.jviromet.2004.09.014

Zhang J, Wang R, Song J, Luo Z, Yang J, Lin F (2013). One-step multiplex RT-PCR for simultaneous detection of four viruses in tobacco. Journal of Phytopathology 161:92-97. https://doi.org/10.1111/jph.12032

Zhang L, Hanada K, Palukaitis P (1994). Mapping local and systemic symptom determinants of cucumber mosaic cucumovirus in tobacco. Journal of General Virology 75:3185-3191. https://doi.org/10.1099/0022-1317-75-113185

Zhu F, Che YP, Zhou YK, Cheng SC, Liu Z, Ji ZL (2018). First report of cucumber mosaic virus infecting Arachis hypogaea in Jiangxi Province in China. Journal of Plant Pathology 100:337. https://doi.org/10.1007/s42161-0180056-4
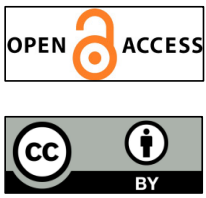

The journal offers free, immediate, and unrestricted access to peer-reviewed research and scholarly work. Users are allowed to read, download, copy, distribute, print, search, or link to the full texts of the articles, or use them for any other lawful purpose, without asking prior permission from the publisher or the author.

License - Articles published in Notulae Botanicae Horti Agrobotanici Cluj-Napoca are Open-Access, distributed under the terms and conditions of the Creative Commons Attribution (CC BY 4.0) License.

(c) Articles by the authors; UASVM, Cluj-Napoca, Romania. The journal allows the author(s) to hold the copyright/to retain publishing rights without restriction. 